\title{
Renal proximal tubular dysfunction is a major determinant of urinary connective tissue growth factor excretion
}

\author{
Karin G. Gerritsen, ${ }^{1}$ Hilde P. Peters, ${ }^{2}$ Tri Q. Nguyen, ${ }^{1}$ Maarten P. Koeners, ${ }^{3}$ Jack F. Wetzels, ${ }^{2}$ \\ Jaap A. Joles, ${ }^{3}$ Erik I. Christensen, ${ }^{4}$ Pierre J. Verroust, ${ }^{5}$ Dongxia Li, ${ }^{6}$ Noelynn Oliver, ${ }^{6}$ Leon Xu, \\ Robbert J. Kok, ${ }^{7}$ and Roel Goldschmeding ${ }^{1}$ \\ Departments of ${ }^{1}$ Pathology and ${ }^{3}$ Nephrology, University Medical Center Utrecht, Utrecht; ${ }^{2}$ Department of Nephrology, \\ Radboud University Nijmegen Medical Center, Nijmegen; ${ }^{7}$ Department of Pharmaceutics, Utrecht Institute for \\ Pharmaceutical Sciences, Utrecht, The Netherlands; ${ }^{4}$ Section of Cell Biology, Department of Anatomy, Aarhus University, \\ Aarhus, Denmark; ${ }^{5}$ Institut de la Vision, Institut National de la Santé et de la Recherche Médicale Unité 968, Paris, France; \\ and ${ }^{6}$ FibroGen, Incorporated, San Francisco, California
}

Submitted 4 December 2009; accepted in final form 15 March 2010

Gerritsen KG, Peters HP, Nguyen TQ, Koeners MP, Wetzels JF, Joles JA, Christensen EI, Verroust PJ, Li D, Oliver N, Xu L, Kok RJ, Goldschmeding R. Renal proximal tubular dysfunction is a major determinant of urinary connective tissue growth factor excretion. Am J Physiol Renal Physiol 298: F1457-F1464, 2010. First published March 17, 2010; doi:10.1152/ajprenal.00694.2009.-Connective tissue growth factor (CTGF) plays a key role in renal fibrosis. Urinary CTGF is elevated in various renal diseases and may have biomarker potential. However, it is unknown which processes contribute to elevated urinary CTGF levels. Thus far, urinary CTGF was considered to reflect renal expression. We investigated how tubular dysfunction affects urinary CTGF levels. To study this, we administered recombinant CTGF intravenously to rodents. We used both full-length CTGF and the $\mathrm{NH}_{2}$-terminal fragment, since the $\mathrm{NH}_{2}$ fragment is the predominant form detected in urine. Renal CTGF extraction, determined by simultaneous arterial and renal vein sampling, was $18 \pm 3 \%$ for full-length CTGF and $21 \pm 1 \%$ for the $\mathrm{NH}_{2}$-fragment. Fractional excretion was very low for both CTGFs $(0.02 \pm 0.006 \%$ and $0.10 \pm 0.02 \%$, respectively), indicating that $>99 \%$ of the extracted CTGF was metabolized by the kidney. Immunohistochemistry revealed extensive proximal tubular uptake of CTGF in apical endocytic vesicles and colocalization with megalin. Urinary CTGF was elevated in megalin- and cubilin-deficient mice but not in cubilin-deficient mice. Inhibition of tubular reabsorption by Gelofusine reduced renal uptake of CTGF and increased urinary CTGF. In healthy volunteers, Gelofusine also induced an increase of urinary CTGF excretion, comparable to the increase of $\beta_{2}$-microglobulin excretion $(r=0.99)$. Furthermore, urinary CTGF correlated with $\beta_{2}$-microglobulin $(r=0.85)$ in renal disease patients $(n=108)$, and only $\beta_{2}$-microglobulin emerged as an independent determinant of urinary CTGF. Thus filtered CTGF is normally reabsorbed almost completely in proximal tubules via megalin, and elevated urinary CTGF may largely reflect proximal tubular dysfunction.

proximal tubular reabsorption; biomarker; megalin

CONNECTIVE TISSUE GROWTH FACTOR (CTGF) is an important profibrotic growth factor in chronic kidney disease (CKD). Elevated urinary connective tissue growth factor levels (uCTGF) are reported in diabetic nephropathy (DN), chronic allograft nephropathy (CAN), IgA nephropathy, focal segmental glomerular sclerosis, and idiopathic membranous nephropathy (iMN) $(1,6,17,24)$. uCTGF relates to markers of

Address for reprint requests and other correspondence: K. G. F. Gerritsen, Dept. of Pathology, Univ. Medical Center Utrecht, P.O. Box 85500, 3508 GA, Utrecht, The Netherlands (e-mail: K.G.F.Gerritsen@umcutrecht.nl). disease severity in CKD. In type I DN, uCTGF excretion correlated with urinary albumin excretion and glomerular filtration rate (GFR) and in CAN with biopsy histology and proteinuria $(6,24)$. In iMN, uCTGF was associated with proteinuria and GFR, and UCTGF was an independent predictor of deterioration of renal function (1). However, despite increasing evidence regarding the biomarker potential of uCTGF, interpretation of urinary levels is hampered by lack of understanding of the processes contributing to elevated levels.

Previously, elevated uCTGF was considered to reflect increased intrarenal production (26). In many renal diseases, overexpression of CTGF was observed in inflammatory glomerular lesions and tubulointerstitial fibrotic areas $(16,31)$. However, we hypothesized that reduced tubular reabsorption might contribute importantly to increased uCTGF excretion. To investigate this, we studied whether CTGF is filtered and tubularly reabsorbed and whether impairment of tubular reabsorption results in increased uCTGF excretion. We quantified renal tubular uptake of recombinant CTGF after intravenous administration in rodents and evaluated the effect of inhibition of proximal tubular reabsorption on UCTGF in healthy rodents and humans. In addition, we examined the correlation between urinary levels of CTGF and $\beta_{2}$-microglobulin $\left(\beta_{2} \mathrm{M}\right)$, a sensitive marker of tubular dysfunction, in renal disease. The secondary objective was to identify the endocytic receptor involved in proximal tubular reabsorption of CTGF.

\section{MATERIALS AND METHODS}

Recombinant CTGF proteins and anti-CTGF antibodies. Recombinant CTGFs and anti-CTGF antibodies were supplied by Fibrogen (San Francisco, CA). The recombinant human CTGFs were produced in a baculovirus expression system in Chinese Hamster Ovary cell lines cultured in hollow-fiber fermentors. The proteins were purified by CTGF-affinity and cation exchange chromatograpy. Recombinant full-length CTGF comprised all four domains (Q27-A349), and the $\mathrm{NH}_{2}$-terminal fragment comprised domains 1 and 2 (Q27-A178).

Gelofusine. We purchased Gelofusine (40 g/l) from Braun (Oss, The Netherlands). Gelofusine is a modified gelatin consisting of polypeptides with an average molecular mass of $30 \mathrm{kDa}$. In previous studies, we have shown that Gelofusine effectively blocks tubular reabsorption of low molecular mass proteins (30).

Animal experiments. Pharmacokinetic studies were performed in mice and rats. All experiments were approved by the Animal Ethical Commission of the University of Utrecht and performed in accordance with national guidelines for the care and handling of animals. 
C57B1/6J mice (12 wk old; Harlan, Horst, The Netherlands) received recombinant human CTGF by tail vein injection (single dose) or by intraperitoneal infusion (3 days) using micro-osmotic pumps (model 1003D; ALZET, Cupertino, CA). To evaluate the plasma disappearance and uptake in the kidneys, mice were killed at various time points after bolus injection of full-length CTGF or $\mathrm{NH}_{2}-\mathrm{CTGF}$ (12.5-50 pmol/g body wt). Kidneys were harvested, weighed, and processed for ELISA or immunohistochemistry, as described below. To evaluate the effects of inhibition of proximal tubular reabsorption, a separate group of mice received Gelofusine ( $40 \mathrm{~g} / \mathrm{l}$; Braun) either by tail vein injection $\left(5 \mu \mathrm{l} / \mathrm{g}\right.$ body wt) $1-2$ min before $\mathrm{NH}_{2}$-CTGF injection in the other tail vein $(n=3)$ or by tail vein injection $(10 \mu \mathrm{l} / \mathrm{g}$ body wt) during $\mathrm{NH}_{2}$-CTGF intraperitoneal infusion $(0.6 \mathrm{pmol} / \mathrm{min})$ by micro-osmotic pump 3 days after intraperitoneal implantation under isoflurane anesthesia $(n=3)$.

To identify the endocytic receptors involved in tubular reabsorption of (endogenous) CTGF, urine was collected during a 24-h period from mice deficient for cubilin or megalin/cubilin, obtained by crossing mice bearing floxed cubilin alleles or both cubilin and megalin floxed alleles with Mox2-Cre mice. Surviving offspring exhibited a mosaic pattern of cubilin deficiency or megalin and cubilin deficiency (11). Deletion of cubilin and megalin varied from $70 \%$ to over $95 \%$. Age-matched wild-type mice were used as controls. Endogenous uCTGF levels were determined by ELISA as described below.

Studies in rats were performed to quantify the renal extraction and fractional excretion (FE). Male Wistar-Kyoto rats (15-17 wk old; Harlan) were anesthetized with intraperitoneal pentobarbital sodium $(72 \mathrm{mg} / \mathrm{kg}$ ). The trachea was intubated with a $16-\mathrm{G}$ catheter (Venisystems Abbocath-T, Abbott, Ireland). A PE-90 catheter was placed in the left jugular vein for infusion of solutions, a second PE-10 catheter was introduced for CTGF infusion, and a third PE-10 catheter for supplemental anesthetic. The left femoral artery was cannulated with PE-90 tubing for blood withdrawal and pressure monitoring. A PE-90 catheter was placed in the bladder for urine collection. The left renal vein was exposed through a ventral midline and left subcostal incision, to make it accessible for puncture. During surgery, animals received intravenous infusion of $0.9 \% \mathrm{NaCl}$ and $6 \%$ BSA followed by $1 \%$ BSA after $20 \mathrm{~min}$ at a rate of $8 \mathrm{ml} \cdot \mathrm{kg}^{-1} \cdot \mathrm{h}^{-1}$. Following surgery, the infusion rate was reduced to $6 \mathrm{ml} \cdot \mathrm{kg}^{-1} \cdot \mathrm{h}^{-1}$ and maintained throughout the experiment. The solution also contained $30 \mathrm{mM}$ Inulin (Inutest; Fresenius Pharma, Linz, Austria) and $25 \mathrm{mM}$ para-aminohippuric acid (PAH; Sigma, St. Louis, MO) for clearance measurements. After a 45-min stabilization period, infusion of full-length CTGF or $\mathrm{NH}_{2}$-CTGF was started at 54 or $7 \mathrm{pmol} \cdot \mathrm{kg}^{-1} \cdot \mathrm{min}^{-1}$, respectively, based on pilot clearance studies. Urine was collected at 15-min intervals. After the start of CTGF infusion (90 min), two arterial blood samples were taken at an interval of $30 \mathrm{~min}$ to determine fractional CTGF excretion. After a short equilibration period, a third arterial blood sample was taken simultaneously with puncture of the left renal vein to determine renal extraction ratios and tubular uptake. Inulin and PAH were measured as described (32).

Human studies. Effect of impairment of tubular reabsorption on uCTGF excretion was studied in healthy human volunteers by infusion of Gelofusine and in renal disease patients with varying degrees of tubular dysfunction. The Gelofusine protocol was approved by the Ethics Review Committee of the University Medical Center St. Radboud, and informed consent was obtained from healthy volunteers. In accordance with Dutch ethical regulations, all patients consented that blood and urine samples were used for medical research. The studies were conducted according to the principles of the Declaration of Helsinki.

Three healthy volunteers received infusion of Gelofusine (40 g/l; Braun), which was started at a rate of $10 \mathrm{ml} / \mathrm{min}$ for $5 \mathrm{~min}$ followed by $3 \mathrm{ml} / \mathrm{min}$ during $55 \mathrm{~min}$. CTGF levels were measured in urinary samples taken before the infusion and at 30,60, and $180 \mathrm{~min}$ after the start of the infusion and in blood samples drawn before and at the end of Gelofusine infusion.
In a cross-sectional study, 108 patients with renal impairment due to glomerular diseases were enrolled from March 1995 through March 2004 at the Department of Nephrology, Radboud University Nijmegen Medical Center (The Netherlands). Details of the cross-sectional study have been described (4).

CTGF ELISA. CTGF levels in plasma, urine, and renal homogenates were determined by sandwich ELISA, using specific antibodies (FibroGen) directed against distinct epitopes in the $\mathrm{NH}_{2}$-terminal fragment of CTGF, detecting both full-length CTGF and the $\mathrm{NH}_{2}$ fragment. Frozen renal tissue (stored at $-80^{\circ} \mathrm{C}$ ) was homogenized in lysis buffer [20 mM Tris (Roche, Mannheim, Germany), $150 \mathrm{mM}$ $\mathrm{NaCl}$ (Merck, Darmstadt, Germany), 1\% Triton X-100, $10 \%$ glycerol, 1 mM EDTA (Riedel-de Haen, Seelze, Germany), 0.1\% SDS (Research Organics, Cleveland, OH), $1 \mathrm{mM}$ EGTA, $0.5 \%$ sodium deoxycholate, $50 \mathrm{mM} \mathrm{NaF}$, and $2 \mathrm{mM}$ sodium orthovanadate (Sigma), $\mathrm{pH}$ 7.4] containing 5\% Protease Inhibitor Cocktail (Sigma). The following two ELISAs were used: a human CTGF assay for detection of endogenous CTGF in human samples or recombinant human CTGF in rodent samples and a rodent CTGF assay for determination of endogenous CTGF in the transgenic mice. For the human CTGF assay, microtiter plates (Maxisorb; Nunc, Roskilde, Denmark) were coated with capture anti-CTGF monoclonal antibody ( $5 \mu \mathrm{g} / \mathrm{ml}$; FibroGen). Subsequently, diluted samples and standards (recombinant human CTGF; FibroGen) were added and incubated with non-cross-blocking human anti-CTGF monoclonal antibody conjugated directly to alkaline phosphatase $(0.5 \mu \mathrm{g} / \mathrm{ml}$; FibroGen $)$. Para-nitrophenylphosphate (Sigma) was used as substrate for the colorimetric reaction. For the rodent CTGF assay, a similar protocol was applied: goat anti- $\mathrm{NH}_{2}$ CTGF polyclonal antibody $(7.5 \mu \mathrm{g} / \mathrm{ml}$; FibroGen) was used for coating, and a non-cross-blocking human anti-CTGF monoclonal antibody was used for detection, followed by incubation with goat anti-human IgG polyclonal antibody conjugated to alkaline phosphatase (1:2,000; Sigma). Recombinant mouse CTGF (FibroGen) was used for standard curves. Assay sensitivities (lower limits of detection) were $0.02 \mathrm{pmol} / \mathrm{ml}$ for the human CTGF assay and $0.04 \mathrm{pmol} / \mathrm{ml}$ for the rodent CTGF assay. The antibody used for detection in the human CTGF assay does not cross-react with rodent CTGF. Intra- and interassay coefficients of variation were within $10 \%$. Plasma levels of endogenous CTGF in healthy rodents, healthy human subjects, and renal disease patients are shown in Supplemental Table 1 (Supplemental data for this article may be found on the American Journal of Physiology: Renal Physiology website.).

In addition to the ELISAs detecting both full-length CTGF and the $\mathrm{NH}_{2}$-fragment, we applied the sandwich ELISA technique to specifically detect full-length CTGF by using two distinct antibodies directed against the $\mathrm{COOH}$-terminal and $\mathrm{NH}_{2}$-terminal fragment. We did not measure significant amounts of full-length CTGF in human or rodent urine, neither in the healthy situation nor in the case of impaired tubular reabsorption, which is in accordance with previous reports $(6,12,19,27)$.

Immunofluorescence. Immunostaining for CTGF was performed on $3 \mu \mathrm{m}$ formalin-fixed paraffin-embedded (FFPE) tissue sections. After deparaffinization, antigen retrieval was performed by predigestion with Protease XXIV (0.2 M phosphate; Sigma) followed by blocking of endogenous peroxidase activity $\left(1 \% \mathrm{H}_{2} \mathrm{O}_{2}\right.$ in phosphate/citrate buffer). Sections were incubated with CTGF-specific human monoclonal antibody (FibroGen) $(24 \mu \mathrm{g} / \mathrm{ml}$ in PBS/1\% BSA) for $1 \mathrm{~h}$ followed by incubation with rabbit anti-human IgG (1:100, $30 \mathrm{~min})$ (Dako, Glostrup, Denmark). Amplification was performed with Powervision polyperoxidase goat anti-rabbit IgG (Klinipath, Duiven, The Netherlands) (30 min) and FITC Tyramide Amplification Reagent (1:50, 10 min) (PerkinElmer, Boston, MA). TO-PRO 3 Iodide (Molecular Probes, Eugene, OR) was used for nuclear counterstaining.

For double immunofluorescence staining for CTGF and megalin, 3 $\mu \mathrm{m}$ deparaffinized FFPE sections were pretreated by boiling in Tris-EDTA buffer, $\mathrm{pH}$ 9.0, and incubated with goat anti-rat megalin 
polyclonal antibody (1:50) (Santa Cruz Biotechnology, Santa Cruz, $\mathrm{CA}$ ) for $1 \mathrm{~h}$ followed by incubation with peroxidase-conjugated rabbit anti-goat IgG (1:50, $30 \mathrm{~min})$ (Dako) and amplification with FITC Tyramide Amplification Reagent (1:50, $10 \mathrm{~min}$ ) (PerkinElmer). Subsequently, sections were incubated with CTGF-specific human monoclonal antibody $(24 \mu \mathrm{g} / \mathrm{ml})$ (FibroGen) for $1 \mathrm{~h}$ followed by incubation with Alexa Fluor 647-conjugated goat anti-human $\operatorname{IgG}(1: 50,30 \mathrm{~min})$ (Molecular Probes).

Slides were mounted in Vectashield (Vector Laboratories, Ontario, Canada) and visualized by confocal laser scanning microscopy. For all stainings, incubation with secondary antibody alone served as a negative control.

Immunohistochemistry. To identify proximal tubules, staining with Lotus tetragonolobus agglutinin (LTA) was applied $(5,28)$. Deparaffinized FFPE sections $(3 \mu \mathrm{m})$ were pretreated by boiling in citrate buffer, $\mathrm{pH}$ 6.0, and incubated with horseradish peroxidase-conjugated LTA (Sigma) (1:32) for $1 \mathrm{~h}$ followed by incubation with NovaRed for $10 \mathrm{~min}$ (Vector Laboratories). Sections were counterstained with hematoxylin and visualized by a Nikon Eclipse E800 microscope (Nikon Netherlands, Lijnden, the Netherlands).

Consecutive sections were stained with LTA and anti-CTGF (see Immunofluorescence). Images of corresponding areas were merged by digital selection and coloring of LTA-positive areas using Adobe Photoshop software version 11.0 (Adobe Systems, San Jose, CA).

Measurement of creatinine. Urinary and serum creatinine were measured with enzymatic assays (J2L Elitech, Labarthe-Inard, France) for murine samples, DiaSys (Holzheim, Germany) for rat samples, and Roche (Mannheim, Germany) for human samples (automated technique).

Measurement of $\beta_{2} M$. u $\beta_{2} \mathrm{M}$ was measured by ELISA, as described before (18). To avoid degradation of $\mathrm{u} \beta_{2} \mathrm{M}$, subjects ingested $4 \mathrm{~g}$ sodium bicarbonate on the evening before the test. $\beta_{2} \mathrm{M}$ was only measured in urine with a urinary $\mathrm{pH}>6.0$.

Calculations and statistics. Data, expressed as means $\pm \mathrm{SE}$, were compared with Student's $t$-test (2-tailed). Paired Student's $t$-test was used for comparison of urinary concentrations in mice and FE in humans before and after Gelofusine administration. Statistical analysis of subsequent urinary concentrations during Gelofusine infusion in humans was performed by ANOVA for repeated measures. Correlations were assessed by linear regression. In the patient study, uCTGF, $\mathrm{u} \beta_{2} \mathrm{M}$, plasma CTGF, and serum creatinine were logarithmically transformed before analysis because of their skewed distribution. Urinary concentrations were expressed in moles per gram of creatinine to correct for differences in urine dilution. GFR was estimated by the abbreviated Modification of Diet in Renal Disease equation (21). Renal clearances and FE were calculated by standard formulas. Renal extraction was calculated as follows:

arterial concentration - renal vein concentration arterial concentration

Tubular uptake was expressed as a percentage of the amount of CTGF extracted by the kidney and calculated as follows:

$$
\left\{1-\frac{\text { urine concentration } \times \dot{V}}{(\text { arterial concentration } \times \mathrm{ERPF})-(\text { renal vein concentration } \times[\mathrm{ERPF}-\dot{V}])}\right\} \times 100 \%
$$

where $\dot{V}$ is the urinary flow rate and ERPF the effective renal plasma flow.

\section{RESULTS}

Plasma CTGF is glomerularly filtered, almost completely reabsorbed by proximal tubules, and only minimally excreted in urine. First, we investigated the fate of recombinant human CTGF that was administered intravenously to healthy mice. Using recombinant human CTGF and human CTGF specific antibodies, we could distinguish between endogenous and exogenous CTGF and exclude contribution of locally produced CTGF to measured tissue levels. We administered both fulllength CTGF and the $\mathrm{NH}_{2}$-terminal fragment but focused our analyses primarily on $\mathrm{NH}_{2}-\mathrm{CTGF}$, since this is the predominant form detected in urine $(6,12,19,27)$. Intravenous bolus injection of $\mathrm{NH}_{2}$-CTGF led to rapid accumulation in the renal cortex (Fig. 1A). Immunofluorescent staining showed abundant $\mathrm{NH}_{2}-\mathrm{CTGF}$ in endocytic vesicles in renal proximal tubular cells (Fig. 1, B-C). Localization in apical vesicles suggested that circulating $\mathrm{NH}_{2}-\mathrm{CTGF}$ was glomerularly filtered and subsequently reabsorbed from the luminal fluid. Recombinant full-length CTGF was also filtered and tubularly reabsorbed (Fig. 1D). LTA and CTGF staining of consecutive sections identified the CTGF-containing segments as proximal tubules (Fig. 2). Thus, in healthy mice, CTGF is glomerularly filtered and to a large extent endocytosed by proximal tubular cells.

To quantify renal extraction and FE, we performed additional experiments in anesthetized rats that received CTGF by continuous infusion. After reaching steady state, kinetic parameters were calculated from steady-state plasma concentrations and urinary excretion, as summarized in Table 1. For determination of renal extraction, blood samples were drawn simultaneously from the renal vein and femoral artery. Renal $\mathrm{NH}_{2}$-CTGF extraction was $21 \pm 1 \%$, which was $74 \%$ of that of inulin. For full-length CTGF, renal extraction was $18 \pm 3 \%$. Tubular uptake was almost complete, resulting in FEs of $<1 \%$ (Table 1). Thus, in healthy rats, renally extracted CTGF is almost completely metabolized by the kidney and minimally excreted in the urine.

Inhibition of tubular reabsorption reduces renal CTGF uptake and increases $u C T G F$ excretion. We next studied the effect of tubular reabsorption impairment on uCTGF. Gelofusine, a modified gelatin clinically applied as a plasma volume expander, was used to inhibit proximal tubular reabsorption $(13,30)$. In mice, intravenous injection of Gelofusine 1-2 min before intravenous bolus injection of $\mathrm{NH}_{2}-\mathrm{CTGF}$ reduced cortical $\mathrm{NH}_{2}-\mathrm{CTGF}$ uptake by $49 \pm 11 \%(P<0.05$; Fig. $3 A)$. Pretreatment with Gelofusine resulted in a comparable decrease in cortical uptake of full-length CTGF (Supplemental Figure). Moreover, a single intravenous bolus dose of Gelofusine during continuous $\mathrm{NH}_{2}$-CTGF infusion by an intraperitoneal miniosmotic pump in mice increased urinary $\mathrm{NH}_{2}$ CTGF $15 \pm 1$-fold $(P<0.05$; Fig. $3 B)$.

In addition to experiments with recombinant CTGFs in mice, we also studied the effect of inhibition of tubular reabsorption on urinary excretion of endogenous CTGF in healthy human volunteers. Although basal levels were low, Gelofusine infusion induced a $23 \pm 1$-fold increase in uCTGF $(P<0.01)$, which was paralleled by an increase in urinary $\beta_{2}$-microglobulin $\left(\mathrm{u} \beta_{2} \mathrm{M}\right)(r=0.99)$ (Fig. $4, A$ and $\left.B\right)$. FE of CTGF increased from $0.47 \pm 0.1$ to $13 \pm 3 \%(P<0.05)$. These results demonstrate that, in healthy subjects, diminished tubular reuptake of CTGF from the luminal fluid is sufficient to induce a significant increase of uCTGF.

In renal disease, elevated $u C T G F$ is tightly associated with tubular dysfunction. To investigate whether uCTGF in renal disease correlated with urine levels of $u \beta_{2} \mathrm{M}$ as a marker of tubular dysfunction, we analyzed urines of 108 patients with renal impairment resulting from glomerular diseases. The patients had varying degrees of tubular dysfunction, as indicated 
Fig. 1. Renal CTGF accumulation after single-dose iv administration of recombinant human CTGF in mice. A: estimated renal $\mathrm{NH}_{2}$-CTGF (N-CTGF) levels at different time points after injection, determined by ELISA. Each dot represents one animal. Curve fitting, performed with GraphPad Prism, was by the one-phase exponential decay model. $B-$ $D$ : immunofluorescence of C57B1/6J kidney by using human anti-CTGF (green) and TO-PRO 3 Iodide for nuclear staining (red), visualized by confocal laser scanning microscopy. $B$ : N-CTGF-treated animal at $10 \mathrm{~min}$ showing abundant $\mathrm{N}-\mathrm{CTGF}$ in proximal tubules, intensely staining the brush border. Magnification $\times 630$. $C$ : N-CTGF-treated animal at 30 min showing abundant N-CTGF positive apical endocytic vesicles in proximal tubular cells. Magnification $\times 1,000$. $D$ : CTGF-treated animal at $6 \mathrm{~min}$ showing CTGF in proximal tubules. Magnification $\times 630$. $E$ : saline-treated animal. Magnification $\times 630$.
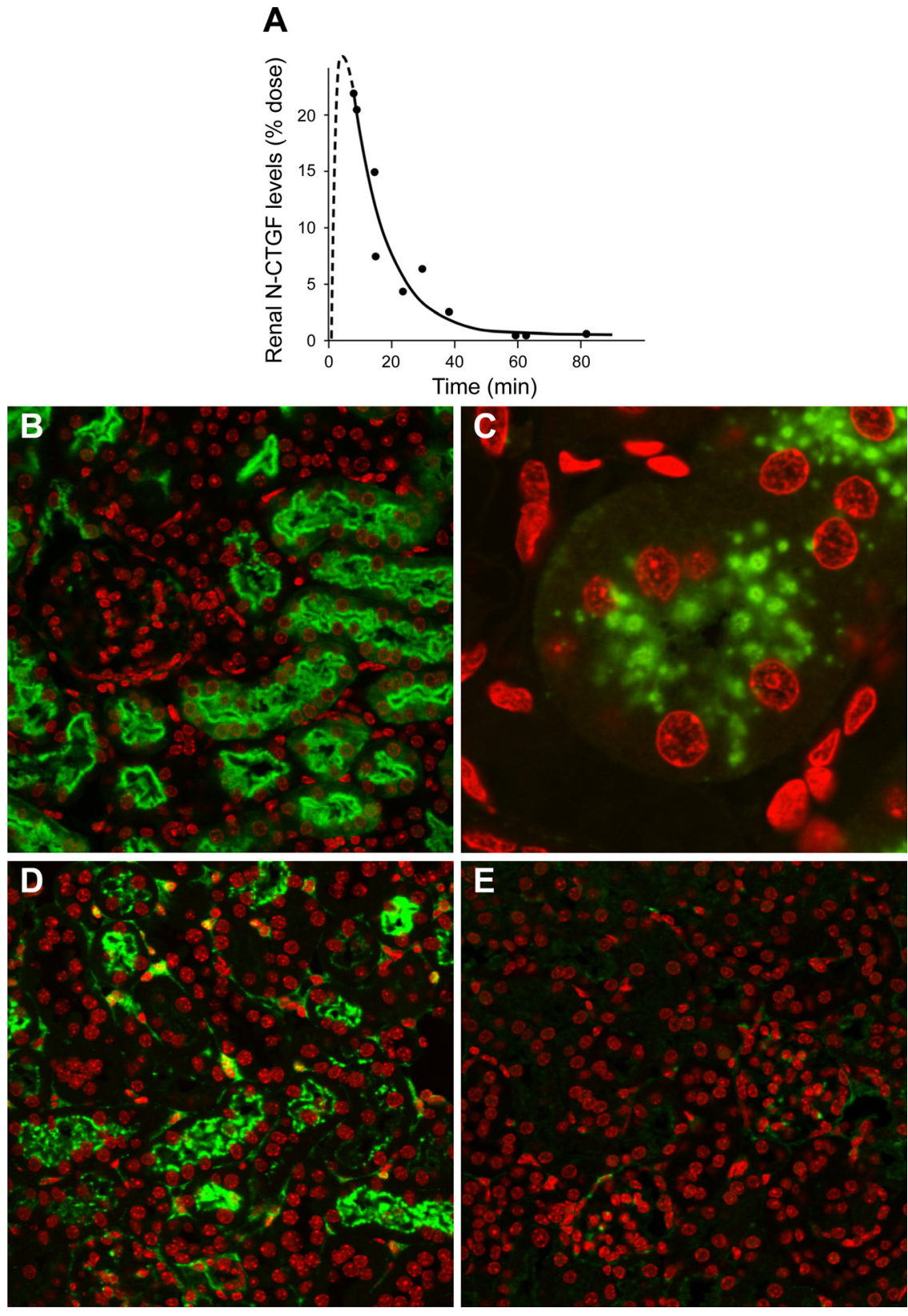

by a wide range of $\mathrm{u} \beta_{2} \mathrm{M}$ levels. General characteristics are summarized in Supplemental Table 2. We observed a tight correlation between uCTGF and $\mathrm{u}_{2} \mathrm{M}(r=0.85, P<0.001$; Fig. 5). u $\beta_{2} \mathrm{M}$ emerged as the only independent determinant of
uCTGF $(\beta$ 0.81, $P<0.001)$ in a multiple linear regression model containing age, estimated GFR (or serum creatinine), and plasma CTGF, which were all significantly associated with uCTGF in univariate analysis. This is strong evidence that
CTGF

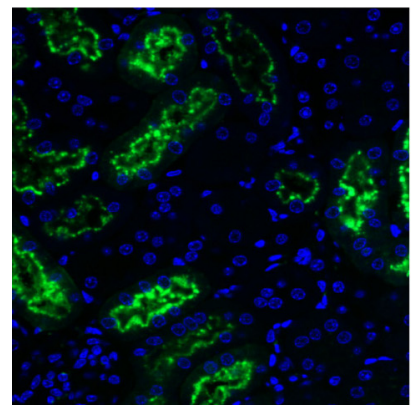

LTA

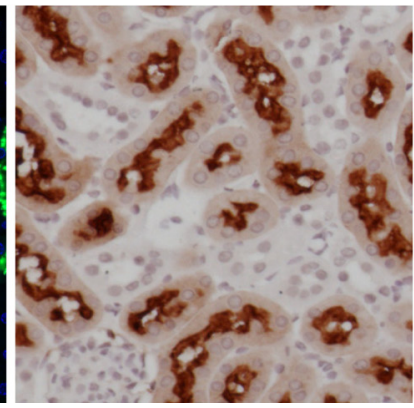

Merge

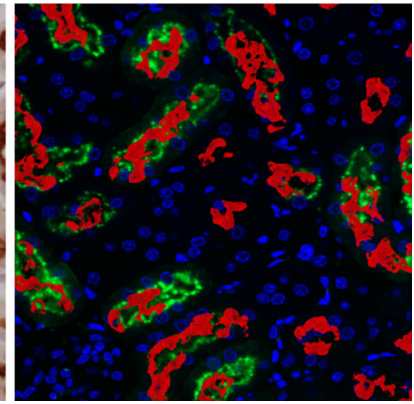

Fig. 2. Colocalization of N-CTGF and Lotus tetragonobolus agglutinin (LTA), a proximal tubule marker. Consecutive sections of mouse kidney after iv administration of recombinant human N-CTGF were stained with human antiCTGF (green) and LTA (red). CTGF-positive endocytic vesicles are located exclusively in LTA-positive proximal tubules. Original magnification $\times 200$. 
Table 1. Renal handling parameters of recombinant human CTGF in healthy rats

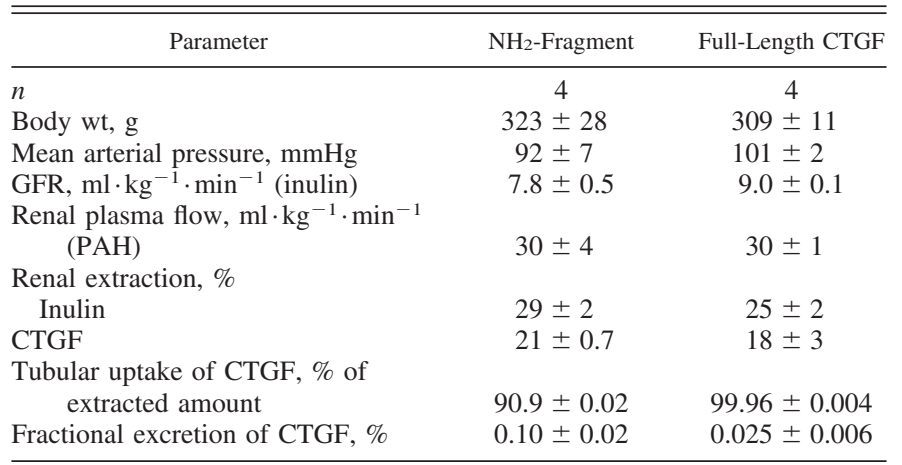

Values are means $\pm \mathrm{SE} ; n$, no. of rats. CTGF, connective tissue growth factor; GFR, glomerular filtration rate; $\mathrm{PAH}$, para-aminohippuric acid.

tubular dysfunction is a major determinant of the uCTGF increase in renal disease.

Megalin is involved in proximal tubular reabsorption of $C T G F$. To identify the endocytic receptor involved in the proximal tubular reabsorption of CTGF, we studied uCTGF in transgenic mice with deficiencies of the endocytic receptors megalin and/or cubilin. These multiligand receptors are known
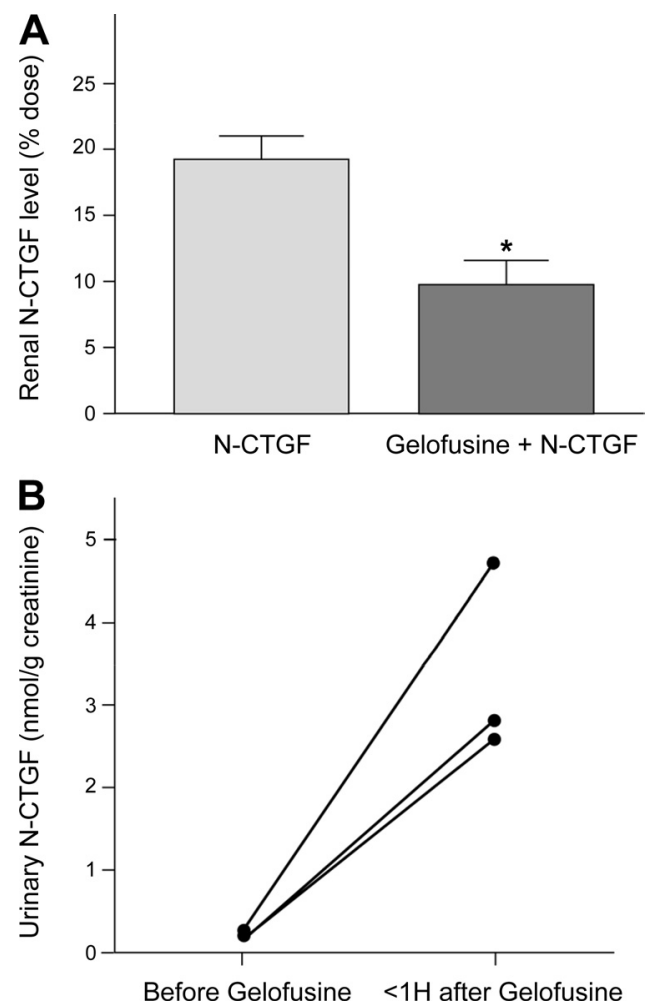

Fig. 3. Effect of inhibition of proximal tubular reabsorption by Gelofusine in mice. A: estimated renal levels of recombinant human N-CTGF 10-15 min after iv N-CTGF administration in mice. Gelofusine administration before $\mathrm{N}-\mathrm{CTGF}$ injection $(n=3)$ reduced renal N-CTGF accumulation compared with saline pretreatment $(n=3)(P=0.03$, unpaired $t$-test $)$. Gelofusine administration did not affect plasma N-CTGF levels. $B$ : urinary N-CTGF levels during continuous infusion of recombinant human N-CTGF by ip miniosmotic pump in 3 mice before ( $16 \mathrm{~h}$ urine collection) and within $1 \mathrm{~h}$ after iv administration of Gelofusine bolus injection. Urinary N-CTGF increased from $0.22 \pm 0.03$ to $3.4 \pm 0.7 \mathrm{nmol} / \mathrm{g}$ creatinine $(P=0.04$; paired $t$-test $)$.
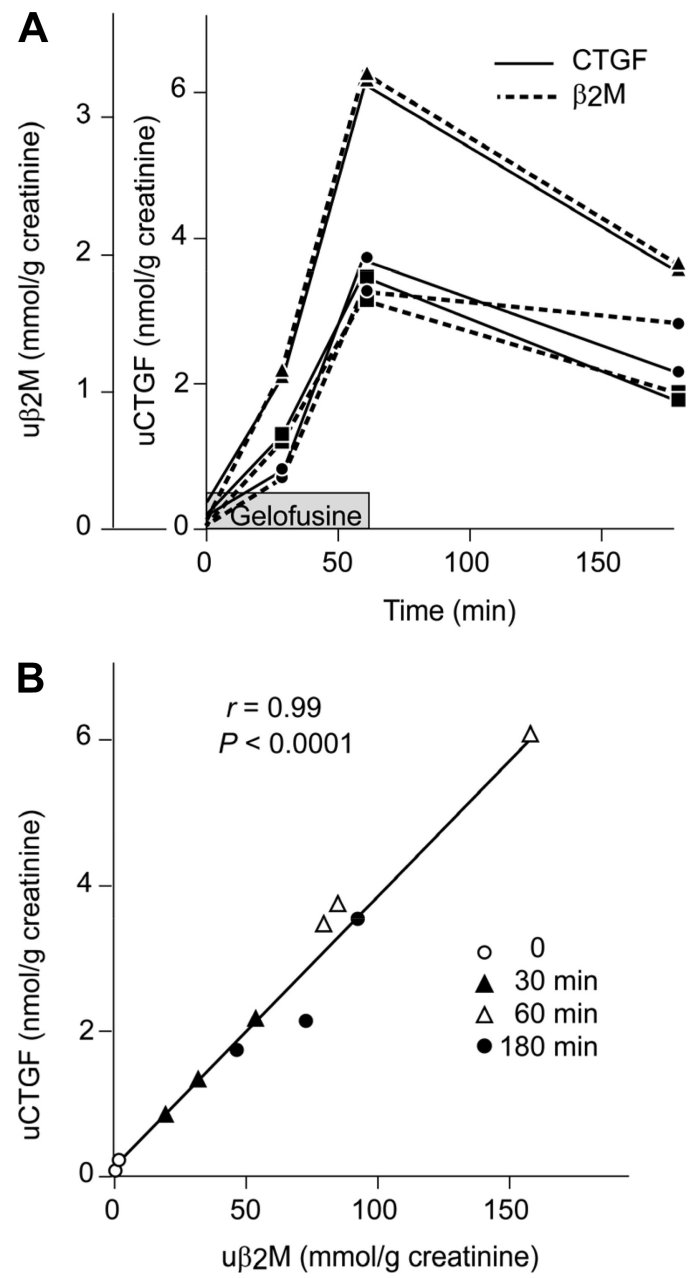

Fig. 4. Effect of inhibition of proximal tubular reabsorption by Gelofusine in humans. A: Gelofusine infusion for $60 \mathrm{~min}$ in 3 healthy volunteers $(\boldsymbol{\Lambda}, \mathbf{O}, \mathbf{\square})$ induced a $23 \pm 1$-fold increase in urinary CTGF (uCTGF) $(P=0.004$; repeated-measures ANOVA) that was paralleled by an increase in urinary $\beta_{2}$-microglobulin $\left(\mathrm{u} \beta_{2} \mathrm{M}\right) . B$ : uCTGF and $\mathrm{u} \beta_{2} \mathrm{M}$ were tightly correlated before, during, and after Gelofusine infusion.

to be responsible for tubular reabsorption of most of the filtered proteins (7). In MOX2-Cre transgenic mice with a mosaic expression pattern of megalin and cubilin in the kidney, exhibiting combined deficiency of both receptors, uCTGF was very high $(14 \pm 1.5 \mathrm{nmol} / \mathrm{g}$ creatinine), whereas, in cubilin knockout and wild-type mice, uCTGF levels were below the level of quantification. There were no differences in plasma CTGF between these various mouse strains. Immunofluorescent staining after intravenous administration of CTGF in healthy $\mathrm{C} 57 \mathrm{Bl} / 6 \mathrm{~J}$ mice revealed colocalization of megalin and CTGF in the cortical (proximal) tubules (Fig. 6). These results show that proximal tubular endocytosis of CTGF is mediated by the multiligand receptor megalin.

\section{DISCUSSION}

The main finding of our studies is that failure of proximal tubular reabsorption is a major determinant of increased uCTGF. In healthy animals, intravenously administered CTGF was filtered in the glomerulus, but only minimal excretion in the urine was observed. This was found to be due to almost 


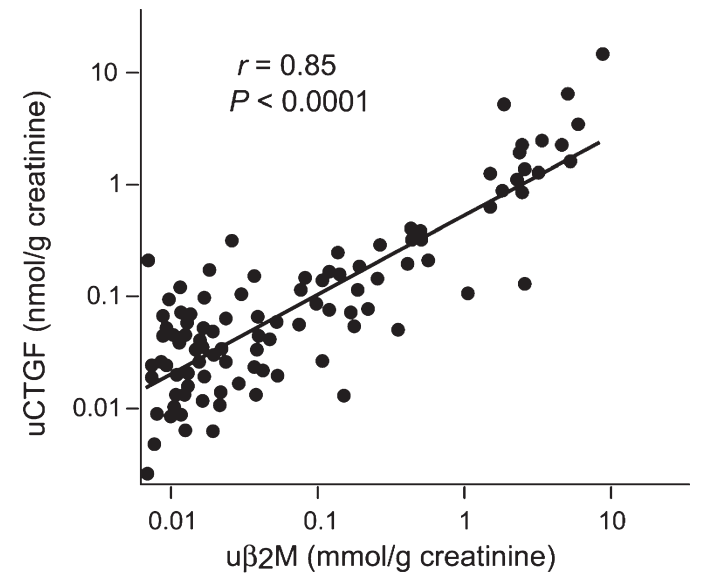

Fig. 5. Correlation between log-transformed uCTGF and $\mathrm{u} \beta_{2} \mathrm{M}$ in 108 chronic kidney disease patients.

complete reabsorption in proximal tubular cells by megalinmediated endocytosis.

Our data show that both full-length and the $\mathrm{NH}_{2}$-CTGF fragment are similarly handled by the kidney. For both CTGFs, we observed extensive proximal tubular uptake in apical endocytic vesicles, very low FE $(<1 \%)$, and almost complete tubular uptake of extracted CTGF $(>99 \%)$. We focused our analyses on the $\mathrm{NH}_{2}$-terminal fragment of CTGF since this is the predominant CTGF peptide in urine $(6,12,19,27)$ and because the biomarker potential of CTGF has been studied most extensively for this proteolytic fragment $(1,2,6,10,12$, $19,24,25,27)$.

After intravenous administration in rats, renal extraction of circulating $\mathrm{NH}_{2}-\mathrm{CTGF}$ was $74 \%$ of that of inulin. Because we found no immunohistochemical evidence for basolateral uptake in proximal tubular epithelial cells, we assume that most of the extracted $\mathrm{NH}_{2}-\mathrm{CTGF}$ was filtered in the primary urine by glomerular sieving, which would imply a sieving coefficient of $\sim 0.7$. This is consistent with the observation that proteins smaller than $20 \mathrm{kDa}$ have sieving coefficients $>0.5$ (22). The high degree of tubular reabsorption of filtered $\mathrm{NH}_{2}-\mathrm{CTGF}$ and low $\mathrm{FE}$ are also in accordance with previously observed values for other low molecular mass proteins, e.g., $\beta_{2} \mathrm{M}$ (fractional reabsorption $99.97 \%$, FE $0.03 \%$ ) and lysozyme (FE 0.4\%) (3, 20, 33).

Impairment of proximal tubular reabsorption, either induced by Gelofusine administration or in human renal disease, was consistently associated with an increase in uCTGF excretion in close correlation with that of $\beta_{2} \mathrm{M}$. Tubular dysfunction is an important parameter in the assessment of renal damage. In CKD, the degree of tubulointerstitial damage and the amount of low molecular mass proteinuria are better predictors of functional outcome than the severity of glomerular damage or the total amount of proteinuria $(8,9)$. In DN, low molecular mass proteinuria was found even before the occurrence of microalbuminuria, probably representing a sign of incipient DN $(9,15)$. Our results imply that uCTGF, reflecting proximal tubular dysfunction, may be a valuable prognostic marker in renal disease. Moreover, in contrast to known proximal tubular dysfunction markers such as the biologically inert $\beta_{2} \mathrm{M}$ and $\alpha_{1}$-microglobulin, luminal accumulation of CTGF and its fragments might contribute actively to the pathogenic process (14, 23). Consistent with such a concept, uCTGF predicted progression of microalbuminuria in diabetic patients (29), and, in another study, uCTGF independently predicted deterioration of renal function in patients with iMN (1). However, the true clinical value of uCTGF in renal disease still needs to be established.

Although we show that uCTGF is highly dependent on tubular function and tightly associated with $\mathrm{u} \beta_{2} \mathrm{M}$, the correlation between the two proteins is not absolute $\left(r^{2}=0.72\right)$. This might reflect disease-associated regulation of CTGF production, either systemically or locally in different segments of the nephron $(16,31)$. As expected for a filtered solute, plasma CTGF was correlated with uCTGF in univariate analysis. However, it did not emerge as an independent determinant in multivariate analysis. The relative contribution of increased local CTGF production could not be determined because the
Fig. 6. Colocalization of N-CTGF and megalin in the mouse kidney. Immunofluorescence of mouse kidney 10 min after iv administration of recombinant human N-CTGF and full-length CTGF by using human antiCTGF (green) and goat anti-megalin (red). The N-terminal fragment and full-length CTGF are located exclusively in megalinpositive proximal tubules. Original magnification $\times 200$.
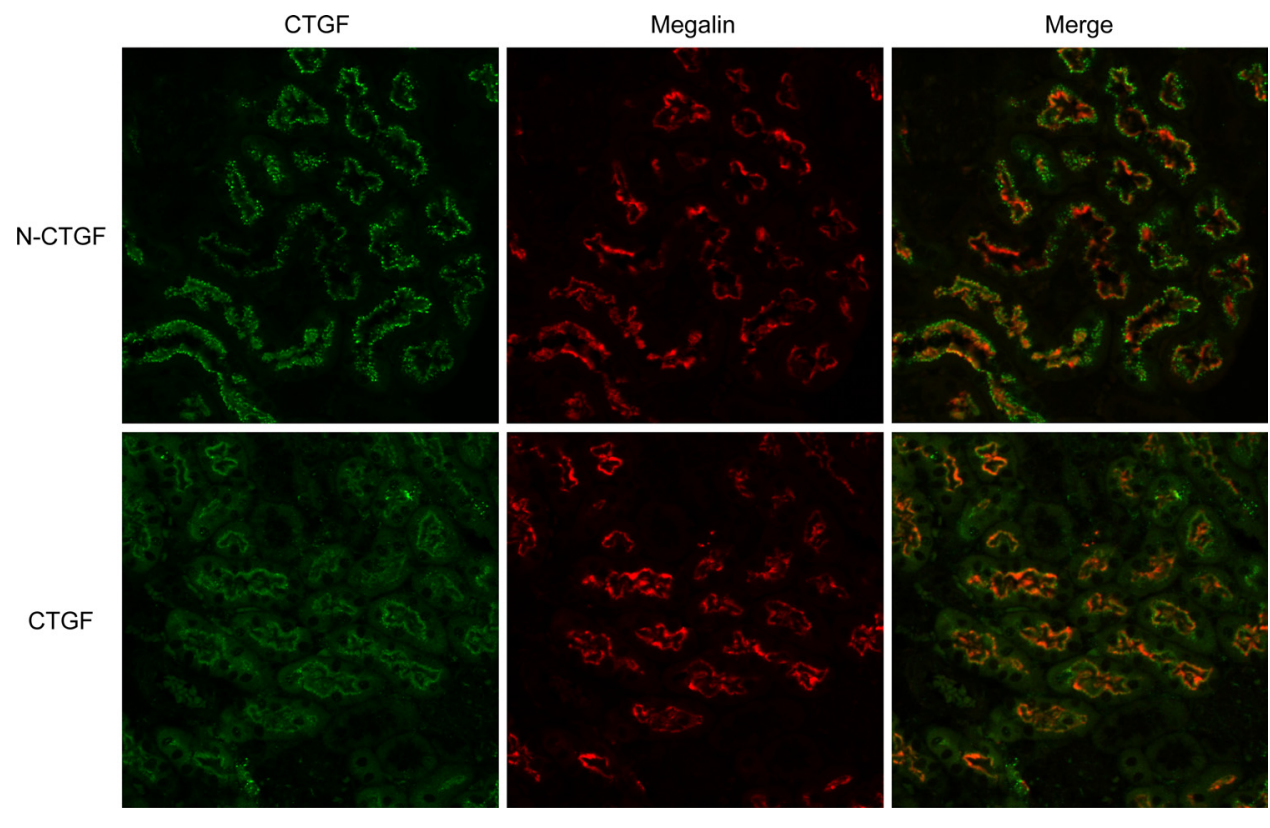
filtered load was unknown. Considering the virtually complete proximal reabsorption from the primary urine in the healthy kidney, CTGF produced in the glomeruli and released in the luminal fluid will have limited impact on UCTGF as long as the proximal endocytic apparatus is intact. On the other hand, luminal secretion of CTGF expressed in distal tubules would be expected to considerably affect uCTGF levels, but the linearity of the relationship between $\mathrm{u} \beta_{2} \mathrm{M}$ and $\mathrm{uCTGF}$ indicates that tubular dysfunction is the major determinant of uCTGF in the renal diseases included in our survey. However, the relative contribution of increased local synthesis on $\mathrm{UCTGF}$ in specific renal diseases remains to be elucidated in future studies.

In conclusion, CTGF is reabsorbed almost completely from the glomerular filtrate in proximal tubules via megalin-mediated endocytosis in the healthy kidney, and elevated uCTGF may largely reflect proximal tubular dysfunction. This should be taken into account when using uCTGF as a biomarker and in experimental work addressing its pathogenic involvement in CKD.

\section{ACKNOWLEDGMENTS}

We thank Marcel Fens, Dionne van der Giezen, Willemiek Kassing-van der Ven, Arianne van Koppen, Jan Willem Leeuwis, Paula Martens, Pia Nielsen, Ebel Pieters, and Kevin van der Ven for technical assistance and support.

\section{DISCLOSURES}

This study was supported by a grant from FibroGen, Inc., a company interested in commercializing anti-CTGF therapies. R. Goldschmeding has been employed by and has received research support from FibroGen. L. Xu and N. Oliver have been employed by and own stock options in FibroGen. D. $\mathrm{Li}$ is employed by and owns stock options in FibroGen.

\section{REFERENCES}

1. Aalten J, Nguyen TQ, Van Nieuwenhoven FA, Goldschmeding R, Wetzels JF. Urinary excretion of connective tissue growth factor predicts deterioration of renal function in patients with idiopathic membranous nephropathy (Abstract). J Am Soc Nephrol 17: 729, 2006.

2. Andersen S, van Nieuwenhoven FA, Tarnow L, Rossing P, Rossing K, Wieten L, Goldschmeding R, Parving HH. Reduction of urinary connective tissue growth factor by Losartan in type 1 patients with diabetic nephropathy. Kidney Int 67: 2325-2329, 2005.

3. Bernard A, Viau C, Ouled A, Tulkens P, Lauwerys R. Effects of gentamicin on the renal uptake of endogenous and exogenous protein in conscious rats. Toxicol Appl Pharmacol 84: 431-438, 1986.

4. Branten AJ, du Buf-Vereijken PW, Klasen IS, Bosch FH, Feith GW, Hollander DA, Wetzels JF. Urinary excretion of beta2-microglobulin and IgG predict prognosis in idiopathic membranous nephropathy: a validation study. J Am Soc Nephrol 16: 169-174, 2005.

5. Cachat F, Lange-Sperandio B, Chang AY, Kiley SC, Thornhill BA, Forbes MS, Chevalier RL. Ureteral obstruction in neonatal mice elicits segment-specific tubular cell responses leading to nephron loss. Kidney Int 63: $564-575,2003$.

6. Cheng O, Thuillier R, Sampson E, Schultz G, Ruiz P, Zhang X, Yuen PS, Mannon RB. Connective tissue growth factor is a biomarker and mediator of kidney allograft fibrosis. Am J Transplant 6: 2292-2306, 2006.

7. Christensen EI, Birn H. Megalin and cubilin: multifunctional endocytic receptors. Nat Rev Mol Cell Biol 3: 256-266, 2002.

8. D'Amico G. Tubulointerstitium as predictor of progression of glomerular diseases. Nephron 83: 289-295, 1999.

9. D'Amico G, Bazzi C. Urinary protein and enzyme excretion as markers of tubular damage. Curr Opin Nephrol Hypertens 12: 639-643, 2003.

10. Dziadzio M, Usinger W, Leask A, Abraham D, Black CM, Denton C, Stratton R. N-terminal connective tissue growth factor is a marker of the fibrotic phenotype in scleroderma. Q J Med 98: 485-492, 2005.
11. Gburek J, Amsellem S, Christensen EI, Verroust PJ, Kozyraki R. Cubilin-independent uptake of apolipoprotein A-1 and transferrin in the renal proximal tubule (Abstract). J Am Soc Nephrol 18: 104, 2007.

12. Gilbert RE, Akdeniz A, Weitz S, Usinger WR, Molineaux C, Jones SE, Langham RG, Jerums G. Urinary connective tissue growth factor excretion in patients with type 1 diabetes and nephropathy. Diabetes Care 26: 2632-2636, 2003.

13. Gotthardt M, van Eerd-Vismale J, Oyen WJ, de Jong M, Zhang H, Rolleman E, Maecke HR, Behe M, Boerman O. Indication for different mechanisms of kidney uptake of radiolabeled peptides. J Nucl Med 48: 596-601, 2007.

14. Grotendorst GR, Duncan MR. Individual domains of connective tissue growth factor regulate fibroblast proliferation and myofibroblast differentiation. FASEB J 19: 729-738, 2005.

15. Holm J, Hemmingsen L, Nielsen NV. Relationship between the urinary excretion of albumin and retinol-binding protein in insulin-dependent diabetics. Clin Chim Acta 177: 101-105, 1988.

16. Ito Y, Aten J, Bende RJ, Oemar BS, Rabelink TJ, Weening JJ, Goldschmeding R. Expression of connective tissue growth factor in human renal fibrosis. Kidney Int 53: 853-861, 1998.

17. Ito Y, Kasuga H, Yoshirou F, Yuzawa Y, Matsuo S, Oliver N, Usinger W, Weitz S, Lomongsod E. Human urinary CTGF (CCN2) as a predictor of progression of chronic renal diseases (Abstract). J Am Soc Nephrol 14: 412, 2003.

18. Jacobs EM, Vervoort G, Branten AJ, Klasen I, Smits P, Wetzels JF. Atrial natriuretic peptide increases albuminuria in type I diabetic patients: evidence for blockade of tubular protein reabsorption. Eur J Clin Invest 29: 109-115, 1999.

19. Jaffa AA, Usinger WR, McHenry MB, Jaffa MA, Lipstiz SR, Lackland D, Lopes-Virella M, Luttrell LM, Wilson PW. Connective tissue growth factor and susceptibility to renal and vascular disease risk in type 1 diabetes. J Clin Endocrinol Metab 93: 1893-1900, 2008.

20. Kirschbaum BB, Sprinkle FM, Oken DE. Renal function and mercury level in rats with mercuric chloride nephrotoxicity. Nephron 26: 28-34, 1980.

21. Levey AS, Greene T, Kusek JW, Beck GJ, Group MS. A simplified equation to predict glomerular filtration rate from serum creatinine (Abstract). J Am Soc Nephrol 11: 0828, 2000.

22. Maack T, Johnson V, Kau ST, Figueiredo J, Sigulem D. Renal filtration, transport, and metabolism of low-molecular-weight proteins: a review. Kidney Int 16: 251-270, 1979.

23. Nguyen TQ, Roestenberg $\mathbf{P}$, van Nieuwenhoven FA, Bovenschen $\mathbf{N}, \mathbf{L i}$ Z, Xu L, Oliver N, Aten J, Joles JA, Vial C, Brandan E, Lyons KM, Goldschmeding R. CTGF inhibits BMP-7 signaling in diabetic nephropathy. J Am Soc Nephrol 19: 2098-2107, 2008.

24. Nguyen TQ, Tarnow L, Andersen S, Hovind P, Parving HH, Goldschmeding R, van Nieuwenhoven FA. Urinary connective tissue growth factor excretion correlates with clinical markers of renal disease in a large population of type 1 diabetic patients with diabetic nephropathy. Diabetes Care 29: 83-88, 2006.

25. Nguyen TQ, Tarnow L, Jorsal A, Oliver N, Roestenberg P, Ito Y, Parving HH, Rossing P, van Nieuwenhoven FA, Goldschmeding R. Plasma connective tissue growth factor is an independent predictor of end-stage renal disease and mortality in type 1 diabetic nephropathy. Diabetes Care 31: 1177-1182, 2008.

26. Riser BL, Cortes P, DeNichilo M, Deshmukh PV, Chahal PS, Mohammed AK, Yee J, Kahkonen D. Urinary CCN2 (CTGF) as a possible predictor of diabetic nephropathy: preliminary report. Kidney Int 64: 451-458, 2003.

27. Roestenberg $\mathbf{P}$, van Nieuwenhoven FA, Wieten L, Boer P, Diekman T, Tiller AM, Wiersinga WM, Oliver N, Usinger W, Weitz S, Schlingemann RO, Goldschmeding R. Connective tissue growth factor is increased in plasma of type 1 diabetic patients with nephropathy. Diabetes Care 27: 1164-1170, 2004.

28. Schulte BA, Spicer SS. Histochemical evaluation of mouse and rat kidneys with lectin-horseradish peroxidase conjugates. Am J Anat 168: 345-362, 1983.

29. Tam FW, Riser BL, Meeran K, Rambow J, Pusey CD, Frankel AH. Urinary monocyte chemoattractant protein-1 (MCP-1) and connective tissue growth factor (CCN2) as prognostic markers for progression of diabetic nephropathy. Cytokine 47: 37-42, 2009.

30. ten Dam MA, Branten AJ, Klasen IS, Wetzels JF. The gelatinderived plasma substitute Gelofusine causes low-molecular-weight proteinuria by decreasing tubular protein reabsorption. J Crit Care 16: 115-120, 2001. 
31. Turk T, Leeuwis JW, Gray J, Torti SV, Lyons KM, Nguyen TQ, Goldschmeding R. BMP signaling and podocyte markers are decreased in human diabetic nephropathy in association with CTGF overexpression. $J$ Histochem Cytochem 57: 623-631, 2009.

32. Verseput GH, Provoost AP, Braam BB, Weening JJ, Koomans HA. Angiotensin-converting enzyme inhibition in the prevention and treatment of chronic renal damage in the hypertensive fawn-hooded rat. $J$ Am Soc Nephrol 8: 249-259, 1997.

33. Viau C, Bernard A, Lauwerys R. Determination of rat beta 2-microglobulin in urine and in serum. I. Development of an immunoassay based on latex particles agglutination. J Appl Toxicol 6: 185-189, 1986.

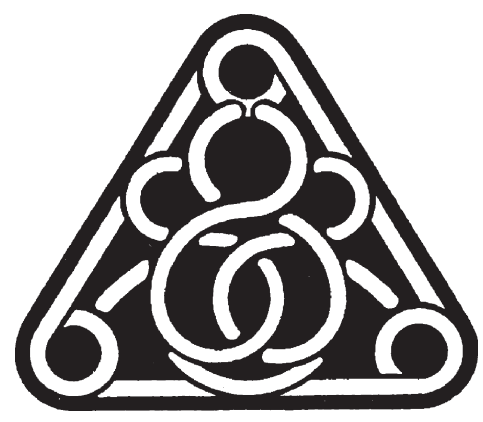

